\title{
A comparative study of the inhibitory effects of purine nucleotides and carboxyatractylate on the uncoupling protein-3 and adenine nucleotide translocase ${ }^{\star}$
}

\author{
Natalia P. Komelina $\bowtie$ and Zarif G. Amerkhanov \\ Laboratory of Mechanisms of Natural Hypometabolic States, Institute of Cell Biophysics, Russian Academy of Sciences, Pushchino, Russia
}

\begin{abstract}
Uncoupling proteins (UCPs) mediate fatty acid-induced proton cycling in mitochondria, which is stimulated by superoxide and inhibited by GDP. Fatty acid anions can also be transported by adenine nucleotide translocase (ANT), thus resulting in the uncoupling of oxidative phosphorylation. In the present work, an attempt was made to distinguish between the protonophoric activity of UCP3 and that of ANT using inhibition analysis. This study was carried out using mitochondria from skeletal muscles of hibernating Yakut ground squirrel, which have a significant level of UCP3 mRNA. We found that millimolar concentrations of GDP, which is considered to be a specific inhibitor of UCPs, slightly recoupled the mitochondrial respiration and restored the membrane potential. Addition of the specific ANT inhibitor CAT (carboxyatractylate), in micromolar concentration, prior to GDP prevented its recoupling effect. Moreover, GDP and ADP exhibited a competitive kinetic behavior with respect to ANT. In brown adipose tissue, CAT did not prevent the UCP1-iduced increase in chloride permeability and the inhibitory effect of GDP, thus confirming the inability of CAT to affect UCP1. These results allow us to conclude that the recoupling effect of purine nucleotides on skeletal muscle mitochondria of hibernating ground squirrels can be explained by interaction of the nucleotides with ANT, whereas UCP3 is not involved in the process.
\end{abstract}

Keywords: uncoupling protein-3 (UCP3), adenine nucleotide translocase (ANT), fatty acid-induced uncoupling, skeletal muscle mitochondria

Received: 31 August, 2010; revised: 05 October, 2010; accepted:20 November, 2010; available on-line: 10 December, 2010

\section{INTRODUCTION}

Fatty acid-induced uncoupling of mitochondria is known to be mediated by some anion carriers, as uncoupling proteins UCPs, adenine nucleotide translocase (ANT) (Andreyev et al., 1989), aspartate/glutamate antiporter (Samartsev et al., 1997) and dicarboxylate carrier (Wieckowski \& Wojtczak, 1997).

Uncoupling proteins (UCPs) are a subfamily of the mitochondrial anion carrier proteins (for review see Ricquier \& Bouillaud, 2000; Nedergaard \& Cannon, 2003). It is well-established that the function of UCP1 is adaptive thermogenesis in brown adipose tissue (Nicholls, 1979; Cannon \& Nedergaard, 2004). UCP1-catalyzed passive proton conductance increases respiration and heat production by returning protons, pumped out by the respiratory chain, to the mitochondrial matrix without ATP synthesis. UCP1 activity is tightly regulated, being inhibited by purine nucleotides and activated by free fatty acids (FFA). Similar properties are inherent in UCP2 and UCP3 homologs. UCP3 is expressed predominantly in skeletal muscles (Boss et al., 1997). Proton conductance through UCP3 can be activated by fatty acids (Jaburek et al., 1999), superoxide (Echtay et al., 2002) and 4-hydroxynonenal (Echtay et al., 2003). Given its high amino-acid sequence identity to UCP1, UCP3 was initially proposed to perform a similar thermogenic function in skeletal muscle. However, mice lacking UCP3 maintain their body temperature in a cold environment (Vidal-Puig et al., 2000).

ANT is also involved in the fatty acid-induced uncoupling (Skulachev, 1991). Experiments with cold-exposed rats have shown this carrier to be responsible for the major part of the thermoregulatory uncoupling in heartmuscle mitochondria (Simonyan \& Skulachev, 1998). Studies on the hibernating ground squirrel have demonstrated the involvement of ANT in skeletal-muscle and liver mitochondria in the thermoregulatory uncoupling and stimulation of respiration during the awakening from torpor (Brustovetsky et al., 1992). It was found that the recoupling effect of CAT carboxyatractylate in muscle mitochondria of ground squirrel dramatically increased during awakening from hibernation (Brustovetsky et al., 1990). This was correlated with increasing of free fatty acid concentration in blood plasma and mitochondria (Brustovetsky et al., 1992).

In the view of the above data, the objective of the present work was to study the involvement of ANT and the tissue-specific UCP3 isoform in the uncoupling of oxidative phosphorylation in skeletal-muscle mitochondria of hibernating ground squirrels. We found that preincubation of these mitochondria with CAT abolished the inhibitory effect of GDP on the FFA-induced uncoupling.

\footnotetext{
* e-mail: komelinanp@mail.ru pean Bioenergetics Conference (Warsaw, 2010); abstract in Biochim Biophys Acta, 1797 (Suppl): 88 (2010).

Abbreviations: ANT, adenine nucleotide translocase; BAT, brown adipose tissue; BSA, bovine serum albumin; CAT, carboxyatractylate; FCCP, carbonyl cyanide $p$-trifluoromethoxyphenylhydrazone; FFA, free fatty acid; $R T$, reverse transcriptase; $T_{b}$, body temperature; $\mathrm{TPP}^{+}$, tetraphenylphosphonium cation; UCP, uncoupling protein; $\Delta \Psi$, mitochondrial transmembrane electric potential
} 


\section{MATERIALS AND METHODS}

Animals. Experiments were carried out with Yakut ground squirrels (Spermophillus undulatus). The animals were captured in Yakutia (North-East Siberia, Russia) in summer and were housed in chambers at $1-5^{\circ} \mathrm{C}$ with a 4/20-h light/dark photoperiod. They were given rodent chow, sunflower seeds, carrots, apple slices and water ad libitum. Body temperature $\left(\mathrm{T}_{\mathrm{b}}\right)$ was monitored with a remote temperature sensor. Upon death, $T_{b}$ was verified with a rectal thermocouple and thermometer. The animals were included into the hibernating group when they remained torpid for $1-15$ days $\left(\mathrm{T}_{\mathrm{b}}=1-7^{\circ} \mathrm{C}\right)$. The group of active squirrels consisted of animals in the middle of interbout arousal episodes $\left(\mathrm{T}_{\mathrm{b}}=37^{\circ} \mathrm{C}\right.$ for $1-7$ days). Further division of the animals into experimental groups was based on the levels of the UCP3 mRNA and UCP3 protein in the skeletal muscle tissue (Boyer et al., 1998; Barger et al., 2006).

Tissue sampling and isolation of mitochondria. Active animals were anesthetized with ethyl ether and rapidly decapitated. Hibernators were euthanized by decapitation without anesthesia. Skeletal muscles were immediately dissected from the hind limbs, weighed and placed in ice-cold isolation medium containing $100 \mathrm{mM}$ $\mathrm{KCl}, 50 \mathrm{mM}$ Tris/ $\mathrm{HCl}$ and $2 \mathrm{mM}$ EGTA, $\mathrm{pH}$ 7.4. Tissue samples were shredded with a sharp blade, minced with sharp scissors, rinsed 4-5 times with the isolation medium, stirred for $2 \mathrm{~min}$ in the isolation medium containing $0.2 \%$ bovine serum albumin (BSA), and gently homogenized using a tissue homogenizer. The homogenate was stirred for $3 \mathrm{~min}$ and centrifuged at $490 \times g$ for $10 \mathrm{~min}$. The supernatant was filtered through a layer of muslin and centrifuged at $11000 \times g$ for $10 \mathrm{~min}$. The crude mitochondrial pellet was resuspended in the isolation medium and resedimented at $10500 \times \mathrm{g}$ for $10 \mathrm{~min}$. Finally, the pellet was resuspended in a small volume of the isolation medium and kept on ice. Protein concentration was determined by the Lowry method.

The interscapular, axillary and cervical brown adipose tissue depots were cleaned from the white adipose, nerve and connective tissues, dissected and pooled in ice-cold $250 \mathrm{mM}$ sucrose, $10 \mathrm{mM}$ Hepes, $0.5 \mathrm{mM}$ EGTA and $0.1 \% \mathrm{BSA}, \mathrm{pH}$ 7.2. Throughout the isolation process, tissue samples were kept at $0-4{ }^{\circ} \mathrm{C}$. They were minced with scissors, homogenized, filtered through gauze and centrifuged at $8500 \times \mathrm{g}$ for $10 \mathrm{~min}$. The supernatant with the floating fat layer was discarded. The pellet was resuspended in the isolation medium containing $0.5 \%$ BSA and centrifuged at $800 \times g$ for $10 \mathrm{~min}$. The supernatant was then centrifuged at $8500 \times \mathrm{g}$ for $10 \mathrm{~min}$ and the resulting mitochondrial pellet was resuspended in the isolation medium. The concentrated mitochondrial suspension was kept on ice and used within $4 \mathrm{~h}$.

Measurements of oxygen consumption and membrane potential. Oxygen consumption was measured using a Clark-type oxygen electrode maintained at $26^{\circ} \mathrm{C}$ and calibrated with an air-saturated assay medium, which was assumed to contain $500 \mathrm{ng}$ atom $\mathrm{O} / \mathrm{ml}$ at $26^{\circ} \mathrm{C}$. Electrode response linearity was routinely checked by following the uncoupled respiration rate in the presence of $0.2 \mu \mathrm{M}$ carbonyl cyanide $p$-trifluoromethoxyphenylhydrazone (FCCP) from $100 \%$ to $0 \%$ air saturation. The respiratory control ratio was calculated as the ratio between the respiration rates at state 3 (with 200 $\mu \mathrm{M}$ ADP) and state 4 . With succinate as substrate, the respiratory control ratio was $3.5 \pm 0.5$. Mitochondria (1 $\mathrm{mg}$ protein) were incubated in $1 \mathrm{ml}$ of the assay medium containing $120 \mathrm{mM} \mathrm{KCl,} 1 \mathrm{mM}$ EGTA, $10 \mathrm{mM}$ Hepes, $3 \mathrm{mM} \mathrm{KH}_{2} \mathrm{PO}_{4}, 3 \mathrm{mM} \mathrm{MgCl}, 4 \mathrm{mM}$ succinate, $3 \mu \mathrm{M}$ rotenone and $3 \mu \mathrm{g} / \mathrm{ml}$ oligomycin, $\mathrm{pH}$ 7.4. Uncoupling of oxidative phosphorylation was initiated by $150 \mu \mathrm{M}$ laurate.

Oxygen consumption and membrane potential $(\Delta \Psi)$ were recorded separately. $\Delta \Psi$ was measured using a tetraphenylphosphonium cation $\left(\mathrm{TPP}^{+}\right)$-sensitive electrode (Kamo et al., 1979). The electrode was calibrated with successive additions of $0.5 \mu \mathrm{M} \mathrm{TPP}^{+}$up to $2 \mu \mathrm{M}$. The reaction was started with $4 \mathrm{mM}$ succinate. At the end of each run, $2 \mu \mathrm{M}$ FCCP was added to dissipate $\Delta \Psi$ and to release all $\mathrm{TPP}^{+}$back into the medium, allowing one to make corrections for a possible electrode drift. Mitochondria $(1 \mathrm{mg}$ protein) were incubated in $1 \mathrm{ml}$ of the assay medium containing $120 \mathrm{mM} \mathrm{KCl}, 1 \mathrm{mM}$ EGTA, $10 \mathrm{mM}$ Hepes, $3 \mathrm{mM} \mathrm{KH} \mathrm{PO}_{4}, 3 \mathrm{mM} \mathrm{MgCl}_{2}, 4 \mathrm{mM}$ succinate, $3 \mu \mathrm{M}$ rotenone and $3 \mu \mathrm{g} / \mathrm{ml}$ oligomycin, $\mathrm{pH}$ 7.4 .

The steady-state levels of ADP were maintained by adding $2.5 \mathrm{U} / \mathrm{ml}$ hexokinase and $10 \mathrm{mM}$ glucose in the absence of oligomycin (Wanders et al., 1994). The rate of mitochondrial respiration was measured at 5, 10, 20, 40, 80 and $160 \mu \mathrm{M}$ ADP. The incubation medium contained mitochondria (1 $\mathrm{mg}$ protein $/ \mathrm{ml}), 120 \mathrm{mM} \mathrm{KCl}, 1 \mathrm{mM}$

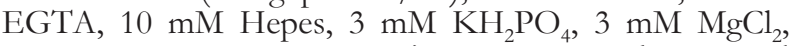
$3 \mu \mathrm{M}$ rotenone, $4 \mathrm{mM}$ succinate, $10 \mathrm{mM}$ glucose and $2.5 \mathrm{U} / \mathrm{ml}$ hexokinase, $\mathrm{pH}$ 7.4. The concentration curves were analyzed following simple Michaelis-Menten kinetics.

Mitochondrial swelling. Swelling of BAT mitochondria was monitored as the change in absorbance at 540 $\mathrm{nm}$ with a Specol spectrophotometer. Swelling of mitochondria (1 $\mathrm{mg}$ protein $/ \mathrm{ml}$ ) was induced by $3 \mu \mathrm{M}$ valinomycin in a medium containing $125 \mathrm{mM} \mathrm{KCl}, 3 \mu \mathrm{M}$ rotenone, $1 \mu \mathrm{M}$ antimycin A, $1 \mathrm{mM}$ EGTA and $10 \mathrm{mM}$ Hepes, pH 7.1 (additions: $250 \mu \mathrm{M}$ GDP and $250 \mu \mathrm{M}$ CAT).

Real-time RT-PCR. Total RNA was isolated from skeletal muscles by a standard guanidinium thiocyanatephenol-chloroform extraction technique. The procedure of real-time quantitative PCR analysis was carried out according to the protocol suggested by the reagentproducing company (Fermentas, Lithuania). Routinely, $7 \mu \mathrm{g}$ of $\mathrm{mRNA}$ were melted with $0.16 \mu \mathrm{M}$ primers for $10 \mathrm{~min}$ at $72^{\circ} \mathrm{C}$, following by primer annealing for 5 min at $58^{\circ} \mathrm{C}$ and addition of $250 \mathrm{mM}$ of Tris/HCl buffer ( $\mathrm{pH}$ 8.3) containing $250 \mathrm{mM} \mathrm{KCl}, 20 \mathrm{mM} \mathrm{MgCl}$, $50 \mathrm{mM}$ dithiothreitol and $0.2 \mu \mathrm{M}$ deoxyribonucleotide triphosphate mixture. The samples were cooled and 20 U of reverse transcriptase M-MulV RT (Fermentas) was added. cDNA synthesis was conducted for $35 \mathrm{~min}$ at $40^{\circ} \mathrm{C}$ and the enzyme was inactivated for $10 \mathrm{~min}$ at $85^{\circ} \mathrm{C}$.

Real-time qPCR was performed with the SYBR Green fluorophore (Invitrogen, USA) using a DT-322 device (DNA-Technology, Russia). The reaction mixture contained $0.3 \mathrm{pM}$ forward and reverse primers, Taq-polymerase buffer $\left(75 \mathrm{mM}\right.$ Tris/ $\mathrm{HCl}, 20 \mathrm{mM}\left(\mathrm{NH}_{4}\right)_{2} \mathrm{SO}_{4}$, $0.01 \%$ Tween-20), $0.1 \mathrm{mM}$ deoxyribonucleotide triphosphate mixture and $1.5 \mathrm{mM} \mathrm{MgCl}, 2 \mathrm{U}$ Taq-DNA-polymerase (Fermentas). The procedure of cDNA amplification was carried out at $94^{\circ} \mathrm{C}$ for $4 \mathrm{~min}$ (denaturation), followed by 3040 -s cycles at $4{ }^{\circ} \mathrm{C}$ (extension), 30-s incubation at $57-59^{\circ} \mathrm{C}$ (annealing), and 4-min incubation at $71^{\circ} \mathrm{C}$ (synthesis of cDNA fragments). Fluorescence was measured at the end of each cycle; the measurements took 15 s. The quantitative analysis (Levik \& Schmitt- 
gen, 2001) of the level of gene expression was carried out with the qPCR program (DNA-Technology).

The quality of isolated RNA was confirmed by $0.8 \%$ agarose gel electrophoresis; RNA was quantified by absorbance at $260 \mathrm{~nm}$ using a NanoDrop spectrophotometer. The specificity of primers and hybridization samples was verified by control reactions in the absence of reverse transcriptase. In these control samples, no fluorescence was detected. The length of the PCR product was confirmed by $5 \%$ PAGE $(260 \mathrm{~V} / 130 \mathrm{~mA})$. Additionally, fragments of cDNA were cut out from the gel and extracted for following the sequence. All amplification fragments were identical with the corresponding gene parts (not shown).

PCR was performed with the following sequence-specific primers (Evrogen, Russia): UCP3_RT: 5'-CGGTCCCCAGGCGCACACTGGC-3'; UCP3_PCR: 5'-GGCCATGGCAGTGACT'TGT-3' ANT_RT: 5'-GCATCATCATACGACGGCGA-3'; ANT_PCR: 5'-TGCTCCCGGATCCCAAGAAT-3'. Gene expression was normalized to $\beta$-actin: $\beta$-actin_RT: 5'-GCTGTGGTGGTGAAGCTGTA-3'; $\beta$-actin_PCR: 5'- 'TTCAACACCCCAGCCATGTA-3'. The primers marked as "RT" were used for cDNA-copy and those marked as "PCR" were used for sample amplification. Primers for UCP3 and $\beta$-actin were selected from the gene sequences of arctic and thirteen-lined ground squirrels (Ensembl Genom Browser). Primers for ANT gene were designed for the conservative parts specific to both ANT isoforms (ANT1 and ANT2) of the rat gene sequence. As revealed by the Blast Search (NCBI), the sequence of all primers was only homologous to the target gene.

All reagents were from Sigma (USA) unless otherwise stated.

Statistics. The data are expressed as means \pm standard errors. Statistical significance was estimated by the Student's $t$-test.

\section{RESULTS}

\section{Expression of UCP3 and ANT mRNAs in skeletal muscles of hibernating and active ground squirrels}

Using real-time qRT-PCR, we have compared hibernating and active animals for the expression of UCP3 and ANT mRNAs in the skeletal muscle tissue. The levels of the UCP3 and ANT mRNAs expression normalized to $\beta$-actin mRNA are presented in Fig. 1. As expected (Boyer et al., 1998; Barger et al., 2006), the expression of UCP3 mRNA in hibernating torpid animals $\left(\mathrm{T}_{\mathrm{b}}=1-7^{\circ} \mathrm{C}\right)$ was three times higher than that in active

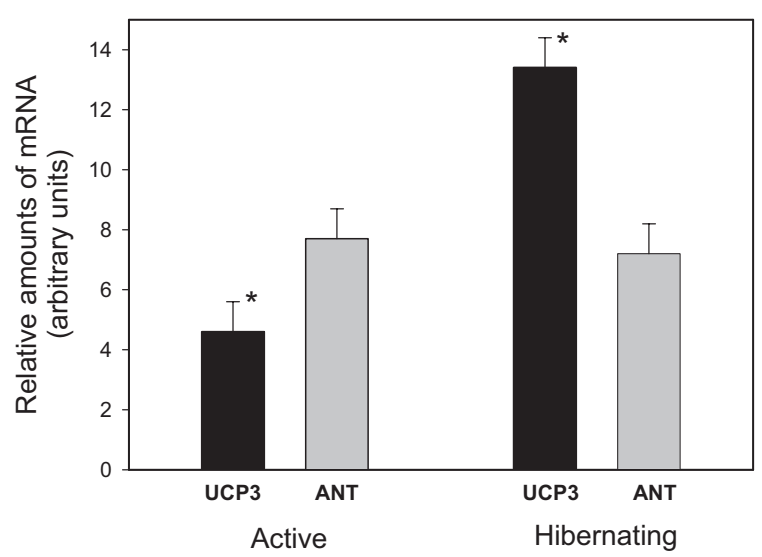

Figure 1. Relative amounts of the UCP3 and ANT mRNAs (arbitrary units) normalized to $\beta$-actin in skeletal muscles of active and hibernating ground squirrels

*Statistically significant differences of UCP3 mRNA between both groups of animals $(P<0.001)$. Differences were non-significant between the levels of ANT $(P>0.05)$. The number of independent experiments $(n=5)$ corresponds to the number of animals.

interbout animals $\left(\mathrm{T}_{\mathrm{b}}=37^{\circ} \mathrm{C}\right)$. The level of ANT mRNA showed no significant differences in these two groups.

\section{Recoupling effect of ADP and CAT on the respiration rate and membrane potential in skeletal-muscle mitochondria of hibernating ground squirrels}

In the presence of oligomycin (to inhibit ATP synthase) and $150 \mu \mathrm{M}$ laurate (to initiate FFA-induced uncoupling), GDP, ADP and CAT were found to recouple respiration and phosphorylation of skeletal-muscle mitochondria of hibernating and active ground squirrels. The degree of the recoupling depended on the order of additions. If $1 \mathrm{mM}$ GDP was added first, we observed a decrease in the rate of FFA-uncoupled respiration (Figs. 2A, E). ADP and CAT added thereafter further decreased the respiration rate. In case of the opposite order of additions, GDP had no effect either when added after CAT (Fig. 2B) or after ADP (Fig. 2F). This effect was observed in both groups of animals (Table 1). The respiration rate was higher in the hibernating animals than in the active animals (Table 1) supplied with the increased concentration of FFA in mitochondria, as shown previously (Brustovetsky et al., 1992).

The FFA-induced increase in the proton conductance and decrease in $\Delta \Psi$ of skeletal-muscle mitochondria from hibernating ground squirrels were inhibited by

Table 1. Respiration rates of skeletal-muscle mitochondria of hibernating and active ground squirrels depending on the order of additions.

\begin{tabular}{|c|c|c|c|c|c|c|c|}
\hline \multicolumn{8}{|c|}{ Respiration (ng atom $\mathrm{O} / \mathrm{min}$ per $\mathrm{mg}$ protein) } \\
\hline \multirow[t]{2}{*}{ Group of animals } & & & \multicolumn{2}{|c|}{ Order of additions: GDP $\rightarrow$ CAT } & \multicolumn{3}{|c|}{ Order of additions: CAT $\rightarrow$ GDP } \\
\hline & & & 1 & 2 & 1 & 2 & \\
\hline & No additions & FA & GDP & CAT & CAT & GDP & FCCP \\
\hline Active & $28 \pm 5$ & $76 \pm 5$ & $69 \pm 3$ & $47 \pm 4^{* *}$ & $50 \pm 6$ & $50 \pm 3$ & $112 \pm 8$ \\
\hline Hibernating & $48 \pm 6^{*}$ & $94 \pm 7$ & $86 \pm 4$ & $68 \pm 5^{* *}$ & $71 \pm 5$ & $70 \pm 4$ & $106 \pm 9$ \\
\hline
\end{tabular}

Experiments were performed in the presence of $3 \mu \mathrm{g} / \mathrm{ml}$ of oligomycin. Additions: $150 \mu \mathrm{M}$ laurate (FA); $2 \mu \mathrm{M}$ CAT; $100 \mu \mathrm{M}$ ADP; $1 \mathrm{mM}$ GDP; $1 \mu \mathrm{M}$ FCCP. Values represent means \pm S.E.M. from 6 independent experiments. Statistical significance: *active versus hibernating groups $(P<0.01) ;{ }^{*}$ inhibitory effect of CAT versus that of GDP $(P<0.05)$. 

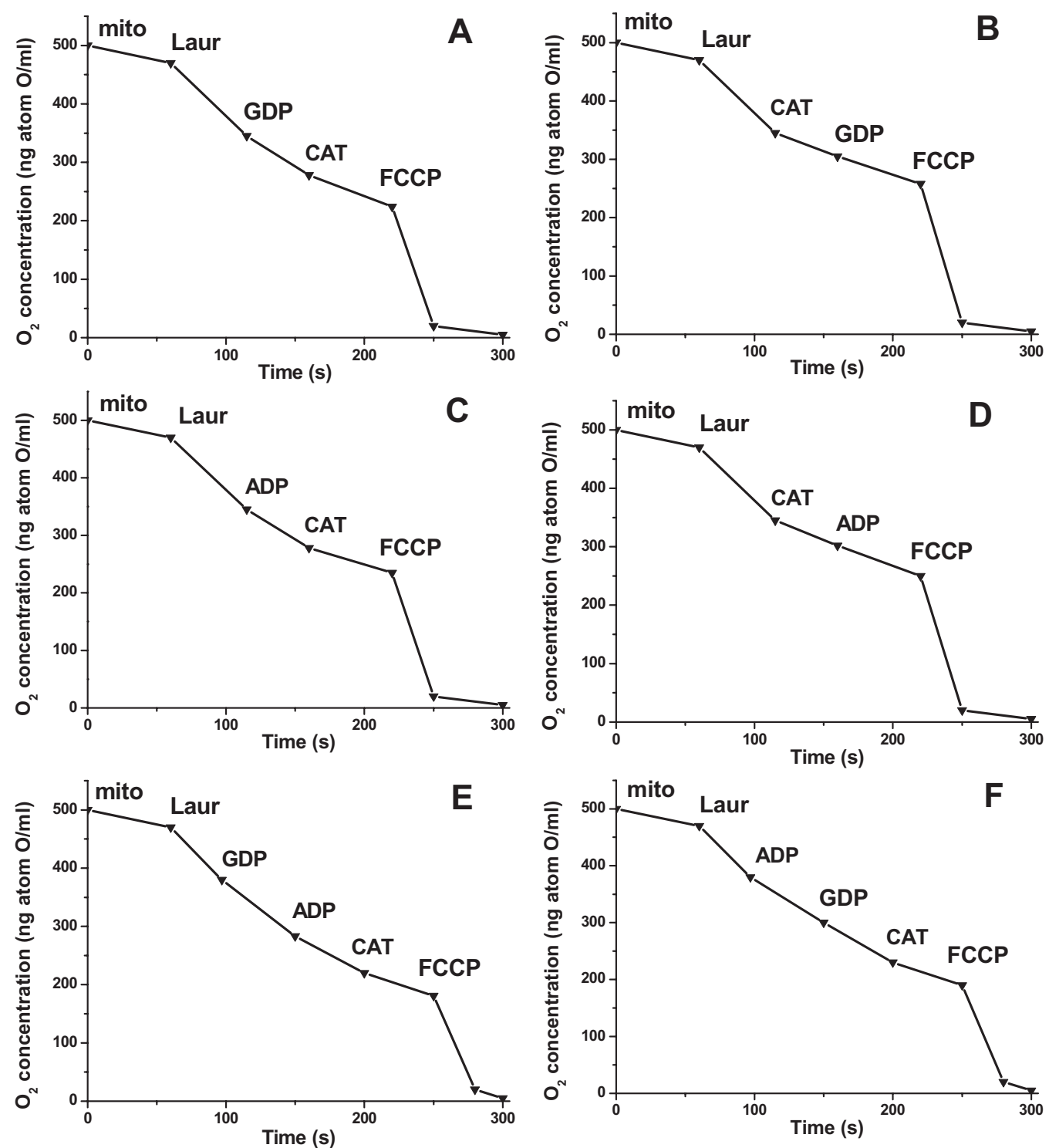

Figure 2. Effects of GDP, ADP and CAT on the respiration rates of skeletal-muscle mitochondria of hibernating ground squirrels depending on the order of additions

Experiments were performed in the presence of $3 \mu \mathrm{g} / \mathrm{ml}$ of oligomycin. Additions: $150 \mu \mathrm{M}$ laurate; $2 \mu \mathrm{M}$ CAT; $100 \mu \mathrm{M}$ ADP; $1 \mathrm{mM}$ GDP; 1 $\mu M$ FCCP.

GDP, ADP and CAT (Figs. 3A, B). It is interesting that CAT almost fully restored $\Delta \Psi$ and completely prevented both the GDP and ADP effects (Figs. 3C, D).

\section{Competitive kinetics of the binding of ADP and GDP to ANT}

The mechanism of inhibition could be examined by measuring the effect of GDP on the rate of oxidative phosphorylation at different steady-state concentrations of ADP (in the presence of hexokinase and excess of glucose). We assume that under these conditions (and in the presence of excess respiratory substrate) the respiration rate is limited by the concentration of ADP. Then, the rate of oxygen consumption should be proportional to the rate of ADP transport by ANT (neglect- ing a small contribution of the proton leak). We found that the GDP-induced inhibition of the respiration increased with decreasing ADP concentration. LineweaverBurk plots showed that $V_{\max }$ versus ADP concentration was the same in the absence and the presence of $1 \mathrm{mM}$ GDP (Fig. 4). This indicates that the transport of ADP via ANT was inhibited competitively by GDP. The $K_{\mathrm{m}}$ value of $12.05 \mu \mathrm{M}$ for ADP corresponds to that known for the ANT-mediated ADP transport (Mak et al., 1983).

\section{Permeability of BAT mitochondrial membrane to chloride and its modulation by GDP and CAT}

The membrane of BAT mitochondria is highly permeable to chloride anions, which can be demonstrated by mitochondrial swelling in a $125 \mathrm{mM} \mathrm{KCl}$ medium in the 

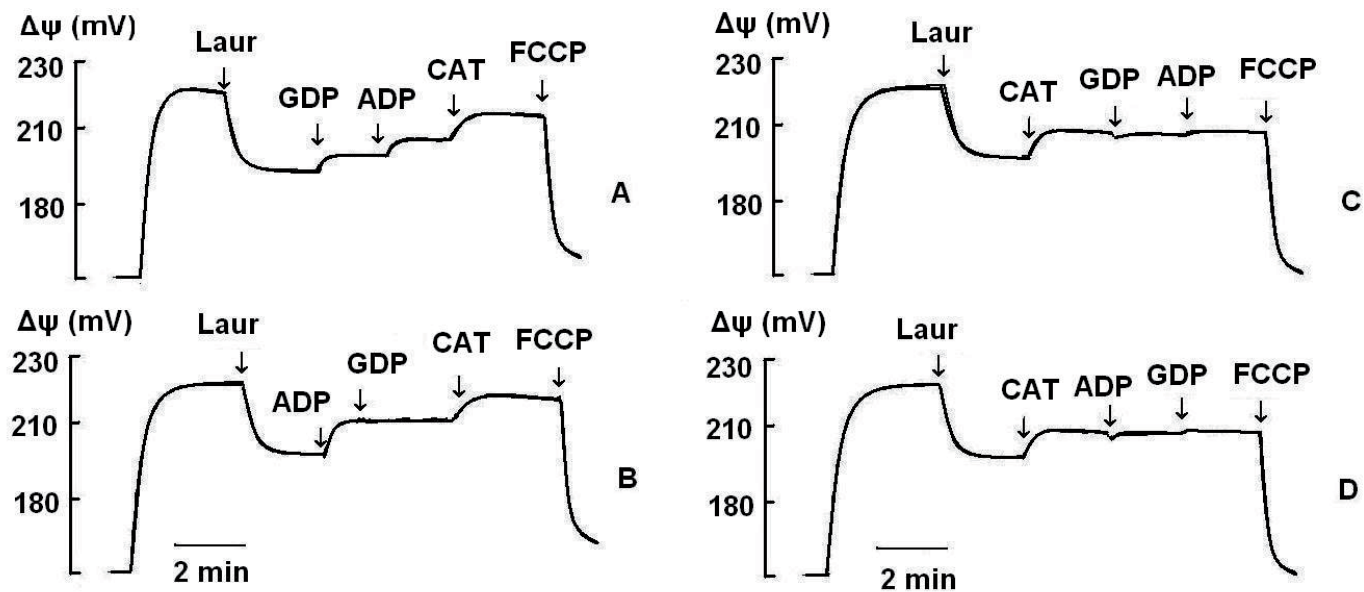

Figure 3. Effects of GDP, ADP and CAT on the membrane potential of skeletal-muscle mitochondria of hibernating ground squirrels depending on the order of additions

Experiments were performed in the presence of $3 \mu \mathrm{g} / \mathrm{ml}$ of oligomycin. Additions: $150 \mu \mathrm{M}$ laurate; $2 \mu \mathrm{M}$ CAT; $100 \mu \mathrm{M}$ ADP; $1 \mathrm{mM}$ GDP; 1 $\mu \mathrm{M}$ FCCP.

presence of valinomycin. GDP is known to inhibit the transport of chloride ions via UCP1. We therefore used BAT mitochondria to investigate possible effects of CAT on the operation of UCPs. Control measurements (Figs. $5 \mathrm{~A}, \mathrm{~B})$ show mitochondrial swelling and its inhibition by low $(250 \mu \mathrm{M})$ GDP concentrations. We found that CAT $(2-250 \mu \mathrm{M})$ was unable to suppress the UCP1-mediated chloride flux and did not prevent the inhibitory effect of GDP (Figs. 5C, D). These data indicate that the only target for CAT action in mitochondria is ANT.

\section{DISCUSSION}

The goal of this study was to distinguish between the role of UCP3 and ANT, proteins belonging to the same anion carrier family, in the FFA-induced uncoupling.

We chose hibernating ground squirrels as the object of our study because their skeletal-muscle mitochondria are rich in UCP3. A high level of UCP3 in skeletal-muscle mitochondria of torpid arctic ground squirrels with $\mathrm{T}_{\mathrm{b}}=1-7^{\circ} \mathrm{C}$ was confirmed by both Northern (mRNA)

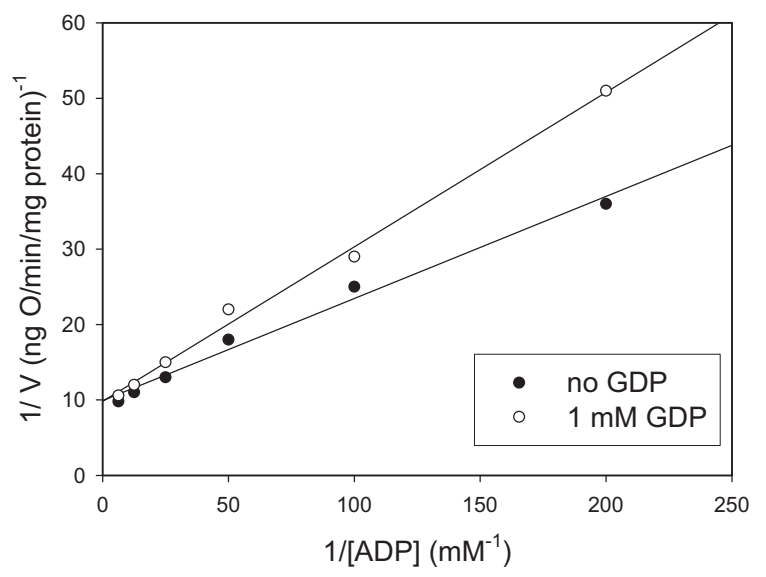

Figure 4. Skeletal-muscle mitochondria of hibernating ground squirrels

Lineweaver-Burk plot of the dependence of the respiration rate on ADP in the absence (black circles) and presence (white circles) of $1 \mathrm{mM}$ GDP. and Western (protein) blot analysis (Boyer et al., 1998; Barger et al., 2006). Using real-time qRT-PCR, we confirmed an increased level of UCP3 mRNA in hibernating torpid Yakut ground squirrels $\left(\mathrm{T}_{\mathrm{b}}=1-7^{\circ} \mathrm{C}\right)$ : it was three times as high as that in active animals (Fig. 1). Since all animals were kept under conditions of strict $T_{b}$ control, we are sure that the hibernating ground squirrels that we experimented with had a high UCP3 level. For UCP3specific effects to be revealed, all experiments also included active animals for control.

We expected that the activation of thermogenesis (either in the process of awakening from hibernation or due to FFA-induced uncoupling) would be accompanied by an increase in the UCP3 activity, manifesting itself by FFA-mediated uncoupling, antioxidant mild uncoupling or transport of oxidation substrates. Should UCP3 be involved, its activity could be revealed by affecting any of the known UCP-attributed features, e.g. inhibition by purine nucleotides (Garlid et al., 2001; Klingenberg \& Echtay, 2001).

Participation of ANT in thermoregulatory enhancement of respiration in skeletal-muscle mitochondria of

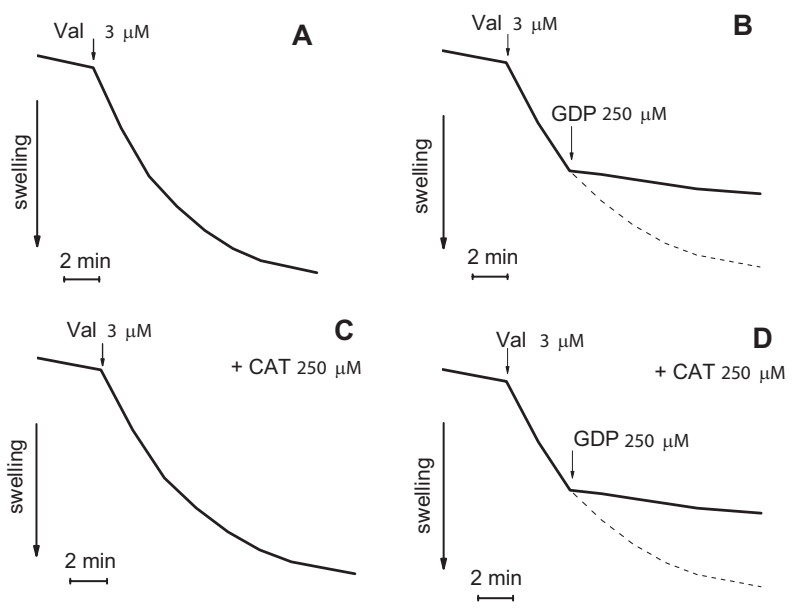

Figure 5. Valinomycin-induced swelling of BAT mitochondria (A) control; (B) inhibition of swelling by $250 \mu \mathrm{M}$ GDP; (C) swelling in the presence of $250 \mu \mathrm{M}$ CAT; (D) inhibition of swelling by 250 $\mu \mathrm{M}$ GDP in the presence of $250 \mu \mathrm{M}$ CAT. 
ground squirrels awaking from hibernation has been demonstrated by Brustovetsky and colleagues (1992). The role of ANT, which is generally accepted to be the main mediator of the uncoupling effect of FFA in liver and muscle mitochondria (Andreyev et al., 1989; Skulachev, 1991), was revealed in a model with lauric acid as the uncoupler and CAT as the specific ANT inhibitor.

We supposed that both UCP3 and ANT could contribute to the FFA-induced increase in the proton conductance of the skeletal-muscle mitochondrial membrane, since, in the presence of oligomycin, mitochondrial respiration was inhibited by both GDP and CAT added in that order (Fig. 2A). Surprisingly, when the order of additions was reversed, $1 \mathrm{mM}$ GDP added after $2 \mu \mathrm{M}$ CAT had no further recoupling effect (Fig. 2B). This effect was observed in both groups, despite the fact that the respiration rates of skeletal-muscle mitochondria were higher in hibernating than in active animals ( $\mathrm{Ta}$ ble 1), assuming activation of all possible mechanisms responsible for uncoupling.

We checked the possibility of CAT to influence the functions of UCPs. We used BAT mitochondria that are rich in UCP1; their membrane has a high chloride permeability, which is inhibited by GDP (Garlid et al., 1996). In this case even very high concentrations (up to $250 \mu \mathrm{M}$ ) of CAT did not affect the UCP1-dependent chloride permeability (in the presence of valinomycin and $\mathrm{KCl}$; Fig. 5C), nor abolished the inhibitory effect of GDP thereupon (Fig. 5D). Therefore, CAT can be considered to affect only ANT and not UCPs (since CAT does not affect UCP1, we can assume the same for its homologs). It has been noted by Brand and coworkers (Parker et al., 2008) that CAT removed the UCP3-dependent proton leak. The molecular mechanism of this effect remains unclear; it might involve protein-protein interactions between ANT and UCP3 or interactions via another component (a protein, lipid or small molecule). On the other hand, CAT is a high-affinity inhibitor of ANT and has not been shown to bind to other proteins (Klingenberg, 2008).

Another observation that attracted our attention was the ability of ADP (in the presence of oligomycin) to prevent the inhibitory effect of GDP in FFA-induced uncoupling in skeletal-muscle mitochondria of hibernating ground squirrels (Fig. 2F). The Lineweaver-Burk plot analysis of this phenomenon (Fig. 4) showed that ADP and GDP affected the respiration in a competitive manner. The inhibition of respiration by GDP increased as the concentration of ADP decreased. This suggests that the transport of ADP by ANT is inhibited in the presence of GDP by a competitive mechanism. Also Skulachev and coworkers (Khailova et al., 2006) demonstrated that GDP inhibited proton translocation by ANT and raised the question about the specificity of GDP effects.

Our results confirm the participation of ANT in the FFA-induced uncoupling in skeletal-muscle mitochondria from hibernating ground squirrels. However, no unambiguous conclusions on the role of UCP3 can be made. In spite of the high level of UCP3 expression in skeletal muscles of hibernating ground squirrels we found no contribution of UCP3 in the FFA-induced uncoupling. Moreover, we conclude that the recoupling effect of GDP is apparently related to a competitive inhibition of ANT as a carrier of ADP and fatty acid anions. Although our findings refer specifically to the role of UCP homologs in the process of hibernation, they are in line with the growing body of evidence suggesting that these proteins are not likely to be physiologically relevant mediators of thermoregulatory uncoupling. Perhaps, the activation of UCP3 by superoxide (Echtay et al., 2002) or hydroxynonenal (Echtay et al., 2003) is essential, according to the hypothesis of Goglia and Skulachev (2003). Nevertheless, observations on the sensitivity of this phenomenon to GDP or CAT should be verified by independent assays for the involvement of UCPs and ANT in the underlying mechanism.

\section{Acknowledgements}

Natalia Komelina was the recipient of a PhD student scholarship from the Russian Fund for Basic Research.

\section{REFERENCES}

Andreyev A, Bondareva TO, Dedukhova VI, Mokhova EN, Skulachev VP, Tsofina LM, Volkov NI, Vygodina TV (1989) The ATP/ADPantiporter is involved in the uncoupling effect of fatty acids on mitochondria. Eur I Biochem 182: 585-592.

Barger JL, Barnes BM, Boyer BB (2006) Regulation of UCP1 and $\mathrm{UCP} 3$ in arctic ground squirrels and relation with mitochondrial proton leak. J Appl Physiol 101: 339-347.

Boss O, Samec A, Paoloni-Giacobino A, Rossier C, Dulloo A, Seydoux J, Muzzin P, Giacobino JP (1997) Uncoupling protein-3: A new member of the mitochondrial carrier family with tissue-specific expression. FEBS Lett 408: 39-42.

Boyer BB, Barnes BM, Lowell BB, Grujic D (1998) Differential regulation of uncoupling protein gene homologues in multiple tissues of hibernating ground squirrels. Am J Physiol Regulatory Integrative Comp Physiol 275: R1232-R1238.

Brustovetsky NN, Amerkanov ZG, Yegorova ME, Mokhova EN, Skulachev VP (1990) Carboxyatractylate-sensitive uncoupling in liver mitochondria from ground squirrels during hibernation and arousal. FEBS Lett 272: 190-192.

Brustovetsky NN, Egorova MV, Gnutov DY, Gogvadze VG, Mokhova EN, Skulachev VP (1992) Thermoregulatory, carboxyatractylate - sensitive uncoupling in heart and skeletal muscle mitochondria of the ground squirrel correlates with the level of free fatty acids. FEBS Lett 305: 15-17.

Cannon B, Nedergaard J (2004) Brown adipose tissue: function and physiological significance. Physiol Rev 84: 277-359.

Echtay KS, Roussel D, St-Pierre J, Jekabsons MB, Cadenas S, Stuart JA, Harper JA, Roebuck SJ, Morrison A, Pickering S, Clapham JC, Brand MD (2002) Superoxide activates mitochondrial uncoupling proteins. Nature 415: 96-99.

Echtay KS, Esteves TC, Pakay JL, Jekabsons MB, Lambert AJ, Portero-Otin M, Pamplona R, Vidal-Puig AJ, Wang S, Roebuck SJ, Brand MD (2003) A signalling role for 4-hydroxy-2-nonenal in regulation of mitochondrial uncoupling. EMBO J 22: 4103-4110.

Garlid KD, Orosz DE, Modriansky M, Vassanelli S, Jezek P (1996) On the mechanism of fatty acid-induced proton transport by mitochondrial uncoupling protein. J Biol Chem 271: 2615-2620.

Garlid KD, Jaburek M, Jezek P (2001) Mechanism of uncoupling protein action. Biochem Soc Trans 29: 803-806.

Goglia F, Skulachev V P (2003) A function for novel uncoupling proteins: antioxidant defense of mitochondrial matrix by translocating fatty acid peroxides from the inner to the outer membrane leaflet. FASEB J 17: 1585-1591.

Jaburek M, Varecha M, Gimeno RE, Dembski M, Jezek P, Zhang M, Burn P, Tartaglia LA, Garlid KD (1999) Transport function and regulation of mitochondrial uncoupling proteins 2 and $3 . \mathrm{J}$ Biol Chem 274: 26003-26007.

Kamo N, Maratsugu M, Hongoh R, Kobatake Y (1979) Membane potential of mitochondria measured with electrode sensitive to tetraphenilphosphonium and relationship between proton electrochemical potential and phosphorylation potential in steady state $J \mathrm{Membr}$ Biol 49: 105-121.

Khailova LS, Prikhodko EA, Dedukhova VI, Mokhova EN, Popov VN, Skulachev VP (2006) Participation of ATP/ADP antiporter in oleate- and oleate hydroperoxide-induced uncoupling suppressed by GDP and carboxyatractylate. Biochim Biophys Acta 1757: 1324-1329.

Klingenberg M (2008) The ADP and ATP transport in mitochondria and its carrier. Biochim Biophys Acta 1778: 1978-2021.

Klingenberg M, Echtay KS (2001) Uncoupling proteins: issues from a biochemist point of view. Biochim Biophys Acta 1504: 128-143.

Livak KJ, Schmittgen TD (2001) Analysis of relative gene expression data using real-time quantitative PCR and the 2(-Delta Delta C(T)) Method. Methods 25: 402-408. 
Mak IT, Shrago E, Elson CE (1983) The influence of linoleic acid intake on the kinetics of adenine nucleotide translocase. Lipids 18: $130-136$.

Nedergaard J, Cannon B (2003) The 'novel' 'uncoupling' proteins UCP2 and UCP3: what do they really do? Pros and cons for suggested functions. Exp Physiol 88: 65-84.

Nicholls DG (1979) Brown adipose tissue mitochondria. Biochim Biopbys Acta 549: 1-29.

Parker N, Affourtit C, Vidal-Puig A, Brand MD (2008) Energizationdependent endogenous activation of proton conductance in skeletal muscle mitochondria. Biochem J 412: 131-139.

Ricquier D, Bouillaud F (2000) The uncoupling protein homologues: UCP1, UCP2, UCP3, StUCP and AtUCP. Biochem J 345: 161-179.

Samartsev VN, Smirnov AV, Zeldi IP, Markova OV, Mokhova EN, Skulachev VP (1997) Involvement of aspartate/glutamate antiporter in fatty acid-induced uncoupling of liver mitochondria. Biochim Biophys Acta 1319: 251-257.
Simonyan RA, Skulachev VP (1998) Thermoregulatory uncoupling in heart muscle mitochondria: involvement of the ATP/ADP antiporter and uncoupling protein. FEBS Lett 436: 81-84.

Skulachev VP (1991) Fatty acid circuit as a physiological mechanism of uncoupling of oxidative phosphorylation. FEBS Lett 294: 158-162.

Vidal-Puig AJ, Grujic D, Zhang CY, Hagen T, Boss O, Ido Y, Szczepanik A, Wade J, Mootha V, Cortright R, Muoio DM, Lowell BB (2000) Energy metabolism in uncoupling protein 3 gene knockout mice. J Biol Chem 275: 16258-16266.

Wanders RJA, Groen AK, Van Roermund CWT, Tager JM (1984) Factors determining the relative contribution of the adenine-nucleotide translocator and the ADP-regenerating system to the control of oxidative phosphorylation in isolated rat-liver mitochondria. Eur J Biochem 142: 417-424.

Wieckowski, MR, Wojtczak L (1997) Involvement of the dicarboxylate carrier in the protonophoric action of long-chain fatty acids in mitochondria. Biochem Biophys Res Commun 232: 414-417. 